\title{
Vaginal hysterectomy a safe option in non-descent uterus as compared to abdominal hysterectomy
}

\author{
Sona Singh ${ }^{1}$, Vishal Gajbhiye ${ }^{2 *}$
}

\begin{abstract}
${ }^{1}$ Department of Obstetrics and Gynecology, ${ }^{2}$ Department of General Surgery, Bundelkhand Medical College, Sagar, Madhya Pradesh, India
\end{abstract}

Received: 05 December 2018

Accepted: 07 February 2019

\author{
*Correspondence: \\ Dr. Vishal Gajbhiye, \\ E-mail: vishal1704@yahoo.com
}

Copyright: () the author(s), publisher and licensee Medip Academy. This is an open-access article distributed under the terms of the Creative Commons Attribution Non-Commercial License, which permits unrestricted non-commercial use, distribution, and reproduction in any medium, provided the original work is properly cited.

\section{ABSTRACT}

Background: The objective of present study was to compare the advantage of vaginal hysterectomy over abdominal hysterectomy in non-descent uterus.

Methods: A non-randomized controlled trial was carried out in the Bundelkhand Medical College, Sagar and associated hospital from October 2015 to September 2017. A total of 150 cases were included in the study. Out on 150, 75 underwent vaginal hysterectomy for non-descent uterus and other 75 underwent abdominal hysterectomy for similar indications.

Results: Among total 150 cases, 75 were underwent non-descent vaginal hysterectomy and similar number of cases underwent abdominal hysterectomy. Common age group was 35-54 years. Commonest indication was DUB (48.7\%). Postoperatively, complications were more common in those who underwent abdominal hysterectomy such as ambulation (18 hours), incidence of nausea, vomiting, abdominal discomfort, bladder injury and wound infection were less in vaginal hysterectomy compared to abdominal hysterectomy. It was also observed that blood transfusion requirement, operative timing and hospital stay (3 days) were less in vaginal hysterectomy group.

Conclusions: Vaginal hysterectomy for benign gynecological disorders is a safe, effective, least invasive and is associated with lesser complications as compare to abdominal hysterectomy. Today in the era where patient is more cosmetically concern, vaginal hysterectomy for non-descent uterine disorder needs to be considered as good and safe option.

Keywords: Nausea, Non-descent uterus and abdominal hysterectomy, Vaginal hysterectomy, Vomiting

\section{INTRODUCTION}

Hysterectomy is one of the most frequently performed elective major surgery in day to day Gynaecological practice. It can be done by open i.e. abdominal or vaginal route and laparoscopic route. Laparoscopy assisted vaginal hysterectomy (LAVH) and total laparoscopic hysterectomy (TLH) although gaining more popularity, is associated with higher cost, longer duration of surgery, and specially trained personnel. ${ }^{1}$ Most of the literature supports the view that vaginal hysterectomy, when feasible, is the safest and most cost-effective procedure for removal of the uterus. ${ }^{2}$ Nevertheless, the abdominal route is the most commonly chosen, $66 \%$ of hysterectomies are performed abdominally, 22\% are performed vaginally, and $12 \%$ are performed laparoscopically. ${ }^{3}$

In today`s world, vigorous attempts are being made to reduce the number of abdominal hysterectomy and replace them with vaginal hysterectomy or laparoscopic assisted vaginal hysterectomy as the next choice. It is 
preferred in high risk cases like obesity and is cosmetically (scar less surgery) superior than abdominal route. Vaginal hysterectomy in larger sized uterus is facilitated by various debulking procedures like bisection, myomectomy, coring and clamp less approach. ${ }^{4}$

The latest value study concluded that major hemorrhage, hematoma, ureteric injury, bladder injury, and anesthetic complications were more in laparoscopic assisted hysterectomy (LAVH) group when compared to abdominal and vaginal hysterectomies. ${ }^{5}$ In addition LAVH was accomplished in twice the time required for vaginal hysterectomy. ${ }^{6}$ Vaginal surgery is least invasive and results in better post-operative quality of life.

In this study authors compared two different techniques of performing hysterectomy i.e. non-descent vaginal hysterectomy and total abdominal hysterectomy (NDVH vs TAH) for benign gynecological indications. The aims and objectives of this study was: to compare vaginal and total abdominal hysterectomy in terms of morbidity and blood loss requiring blood transfusion, to compare the intra-operative and postoperative complications following vaginal and total abdominal hysterectomy, to compare vaginal and total abdominal hysterectomy in term of postoperative hospital stays.

\section{METHODS}

A non-randomized controlled trial was conducted in the department of Obstetrics and Gynecology and Surgery, Bundelkhand Medical College and associate hospital, sagar, Madhya Pradesh, India from October 2015 to September 2017.The female patients with an indication to hysterectomy undergoing hysterectomy in Bundelkhand medical college, sagar and associated hospital. A total of 150 cases satisfying our inclusion criteria were enrolled from amongst women admitted in ward for hysterectomy after taking informed consent from them. Total 75 cases giving consent for vaginal hysterectomy were included in the study group and 75 cases who underwent conventional abdominal hysterectomy were kept in the control group.

\section{Inclusion criteria}

- Patients requiring hysterectomy for benign gynecological disorders without prolapse

- Uterine size not exceeding 12 weeks of gravid uterus

- Adequate vaginal access

- No serious/complicated medical disease.

\section{Exclusion criteria}

- Cases with prolapsed of any degree

- Patients with severity restricted uterine mobility,

- Complex adnexal mass,

- Suspicion of malignancy,

- Vaginal inaccessibility (defined by an extremely tight introitus),

\section{- Cervical fibroid}

Patient's age, parity, weight, menstrual history and presenting complaints were noted. Complete general, physical and pelvic examinations were performed before surgery, every patient was investigated.

The investigations included: haemoglobin, urine analysis for albumin, sugar, microscopy, blood group and $\mathrm{Rh}$ typing, blood sugar, blood urea, serum creatinine, HIV, HbsAg, chest X-ray, ECG, USG -abdomen and pelvis, pap smear

Written informed consents were taken from all patients after explaining the procedure. Every patient was completely evaluated by an anaesthesiologist.

Vaginal hysterectomy was done by Haeney's technique. For abdominal hysterectomy, a supra-pubic transverse incision was given. Operating time for vaginal hysterectomy was calculated from incision at cervicovaginal junction to the completion of closure of vault. Operating time for abdominal hysterectomy was calculated from incision on the abdomen to closure of skin incision.

\section{Statistical analysis}

Fisher's exact test/chi square test was sued to compare independent proportions and independent t test was used to compare means using SPSS version 20.P-value less than 0.5 was considered significant.

\section{RESULTS}

The present study included 150 women undergoing hysterectomy, 75 were subjected to vaginal hysterectomy and 75 were subjected to abdominal hysterectomy. As describe in Table 1, Majority of the patients were in the range of 35-54 years. In vaginal hysterectomy majority cases were in age group 45-54 and in abdominal 35-44. In the vaginal group, minimum age was 34 and maximum age was 56. In the abdominal group, minimum age was 32 and maximum age was 53. Mean age in the vaginal group is $48.66 \pm 8.423(\mathrm{SD})$ and $44.33 \pm 7.587(\mathrm{SD})$ in the abdominal group.

Table 1: Age distribution.

\begin{tabular}{|l|l|l|}
\hline Age & VH $n(\%)$ & AH $n(\%)$ \\
\hline Less than 34 years & $6(8)$ & $12(16)$ \\
\hline 35-44 years & $24(32)$ & $35(46.66)$ \\
\hline 45-54 years & $35(46.66)$ & $20(26.66)$ \\
\hline 55 years and above & $10(13.33)$ & $8(10.66)$ \\
\hline Total & $75(100)$ & $75(100)$ \\
\hline$($ Chi=8.36 p=0.039) & & \\
\hline
\end{tabular}

Most of the women of premenopausal age preferred to undergo abdominal hysterectomy and the difference was significant. 
Table 2: Parity distribution.

\begin{tabular}{|l|l|l|}
\hline Parity & VH $n(\%)$ & AH n (\%) \\
\hline 0 & $4(5.3)$ & $7(9.3)$ \\
\hline 1 & $6(8)$ & $5(6.66)$ \\
\hline 2 & $30(40)$ & $35(46.66)$ \\
\hline 3 & $21(28)$ & $26(34.66)$ \\
\hline 4 & $12(16)$ & $10(13.33)$ \\
\hline 5 & $2(2.66)$ & $2(2.66)$ \\
\hline Total & 75 & 75 \\
\hline
\end{tabular}

Chi $=1.38, \mathrm{p}=0.925$

As shown in Table 2, hysterectomy (Vaginal or abdominal) is common in parity 02 , and there was no significant difference.
Table 3: Diagnosis.

\begin{tabular}{|l|l|l|}
\hline Diagnosis & VH $\mathbf{n}(\%)$ & AH n (\%) \\
\hline DUB & $35(46.66)$ & $39(52)$ \\
\hline Fibroid & $28(37.33)$ & $27(36)$ \\
\hline Adenomyosis & $8(10.66)$ & $6(8)$ \\
\hline PID & $4(5.33)$ & $3(4)$ \\
\hline total & 75 & 75 \\
\hline
\end{tabular}

Chi $=0.66, p=0.88$, Not significant

Table 3 shows, commonest indication for both vaginal and abdominal hysterectomy is DUB followed by Uterine fibroid.

Table 4: Complications in VH and AH group in NDVH.

\begin{tabular}{|l|l|l|l|l|}
\hline Complication & VH n $(\%)$ & AH n $(\%)$ & $\begin{array}{l}\text { Chi square/ Fisher } \\
\text { exact test, p value }\end{array}$ & Significance \\
\hline Haemorrhage requiring blood transfusion & $6(8)$ & $12(16)$ & 0.2082 & Not significant \\
\hline Bladder injury & $2(2.66)$ & $5(6.66)$ & 0.4419 & Not significant \\
\hline UTI & $1(1.33)$ & $6(8)$ & 0.1162 & Not significant \\
\hline Nausea / vomiting & $4(5.33)$ & $16(20.8)$ & 0.0070 & Significant \\
\hline Abdominal distention & $4(5.33)$ & $10(13.33)$ & 0.1587 & Not significant \\
\hline Wound infection & $2(2.66)$ & $8(10.66)$ & 0.0976 & Not significant \\
\hline
\end{tabular}

In the Table 4, there were 6 cases of haemorrhage requiring blood transfusion in vaginal group and 12 cases of haemorrhage requiring blood transfusion in abdominal. There were 2 case of bladder injury in vaginal group and 5 in abdominal. In the present study, post-operative complications like, UTI, abdominal discomfort and wound infection were more common in abdominal cases, but the difference was found to be statistically nonsignificant. Nausea, vomiting was significantly higher in abdominal hysterectomy $(\mathrm{p}=0.0070)$.

Table 5: Ambulation.

\begin{tabular}{|c|c|c|}
\hline Duration of ambulation & VH n $(\%)$ & $\mathbf{A H} \mathbf{n}(\%)$ \\
\hline $\begin{array}{l}\text { Less than } 12 \text { hours after } \\
\text { surgery }\end{array}$ & $25(33.33)$ & $2(2.66)$ \\
\hline 12 to 24 hours & $40(53.33)$ & $15(20)$ \\
\hline $\begin{array}{l}\text { More than } 24 \text { hours after } \\
\text { surgery }\end{array}$ & $10(13.33)$ & $58(77.33)$ \\
\hline Total & 75 & 75 \\
\hline
\end{tabular}

Chi $=64.83, p<0.0001$, Highly significant

As shown in Table 5, majority of the patients in the vaginal group ambulated within 24 hours, while abdominal group ambulated after 24 hours. Mean time taken for ambulation in vaginal group is $18 \pm 4.81$ and abdominal group is $32.06 \pm 5.37$ which was statistically significant.
Table 6: Surgical results.

\begin{tabular}{|l|l|l|}
\hline Parameter & VH & AH \\
\hline Average operating time & $\begin{array}{l}50.43 \pm 7.256 \\
\text { min }\end{array}$ & $\begin{array}{l}86.6 \pm 8.363 \\
\text { min }\end{array}$ \\
\hline $\begin{array}{l}\text { Patient required blood } \\
\text { transfusion due to } \\
\text { hemorrhage }\end{array}$ & 6 & 12 \\
\hline $\begin{array}{l}\text { Average hospital stays in } \\
\text { days }\end{array}$ & 3 & 5 \\
\hline
\end{tabular}

Table 6 shows, vaginal group was associated with less operative time, less intra-operative bleeding and early hospital discharge of patients.

\section{DISCUSSION}

As compare to abdominal approach, vaginal approach to hysterectomy has been gaining popularity among surgeons. now a day's patients are desperate to avoid an abdominal incision and demand scarless surgery. Vaginal route allows the surgeon to operate by the least invasive route of all, utilizing an anatomical orifice. Unfortunately, $70 \%$ to $80 \%$ of hysterectomies are performed by abdominal route and vaginal approach is usually reserved for uterovaginal prolapse. ${ }^{7} \mathrm{With}$ adequate vaginal access and good uterine mobility, vaginal hysterectomy can be easily performed. 
In present study majority of the patients were in the age group of 35-54 year, in vaginal hysterectomy majority cases were in age group 45-54 and in abdominal 35-44. Similar age prevalence was noted in other case series reviews. ${ }^{8-11}$ In Dewan $\mathrm{R}$ et al study, the mean age of abdominal group was 43.7 and vaginal group was 41 . A 7 years, most of their patients were in the age group of 4049 years of age which is well compared with our study. ${ }^{8}$ Similar comparison is found in Mehla S et al, study with majority of patient is in age group of 41-45 year. ${ }^{11}$

In the present study, hysterectomy (vaginal or abdominal) is common in parity 02 , and there was no significant difference, which is comparable to other studies. ${ }^{8-11}$

Commonest indication of NDVH in our study was DUB which is similar to study done by Mehla $\mathrm{S}$ et al, with DUB $(45.7 \%)$ and Purohit RK et al. ${ }^{11,12}$ In our study fibroid uterus is second common indication for $\mathrm{NDVH}$, whereas fibroid uterus was commonest indication in case series by Dewan et al, Bharatnur et al. ${ }^{8,9}$

When duration of surgery was measured it was reported that mean time period of operation in $\mathrm{VH}$ group was less than one hour while in $\mathrm{AH}$ group it is more than one hour. For VH mean time taken was $50.43 \pm 7.256$ min and for $\mathrm{AH} 86.6 \pm 8.363 \mathrm{~min}$. Study by Bharatnur, showed that majority of cases $(72 \%)$ the maximum operating time was between $60-120 \mathrm{~min}$ in TAH Group where as in NDVH Group (68\%) the time taken was 60 min. Mean time taken for abdominal hysterectomy was $101 \pm 27.1$ whereas vaginal hysterectomy was $65 \pm 26.2$ in their study. ${ }^{9}$ Dorsey et al, in his study showed that duration of surgery was 30 minutes longer for TAH than for $\mathrm{VH}{ }^{13}$ The e VAL trial showed that average duration of surgery in abdominal group was 50 minutes and vaginal group was 39 minutes. $^{14}$ Chen $\mathrm{B}$ et al, noted that mean operating time was significantly shorter in vaginal group (mean 65.2 minutes) than in abdominal group (mean 95.6 minutes). ${ }^{15}$ In the present study, the mean operating time for non-descent vaginal hysterectomy was less than TAH group. The present study is well correlated with other studies mentioned above.

Aniuliene et al, in their study concluded that significantly higher blood loss was observed during abdominal hysterectomy as compared to vaginal hysterectomy. ${ }^{16}$ Chen B et al, reported significantly less blood loss in vaginal group (mean $30.4 \mathrm{ml}$ ) compared to abdominal group (mean $70.3 \mathrm{ml}$ ). ${ }^{15}$ The blood transfusion due to blood loss in TAH group in our study was required in 12 patient as compare to 6 in the NDVH group. This study revels more amount of blood loss in TAH as compared to NDVH and authors could correlate this study with similar studies that comparing the abdominal and vaginal routes for hysterectomy and found that amount of blood loss was more in the abdominal route.

As reported by Goswami $\mathrm{D}$ et al, in the TAH group $12.5 \%$ cases developed UTI, $7.5 \%$ developed febrile morbidity, wound gaping 5\% and required of blood transfusion was $7.5 \% .{ }^{17}$ Bharatnur et al, in their study showed that overall post-operative complications are more in abdominal hysterectomy as compared to NDVH. ${ }^{9}$

In present study in the TAH group $8 \%$ cases developed UTI, wound infection $10.66 \%$, abdominal distension $13.33 \%$ and blood transfusion $16 \%$. In all the above studies including our study, complications are more common in abdominal hysterectomy as compare to vaginal hysterectomy.

The length of hospital stay reported by Dorsey et al, was 3.5 days. ${ }^{13}$ In Shachi et al, study, Mean postoperative stay in vaginal group was $3.77 \pm 1.18$ days and $5.02 \pm 1.35$ days in the abdominal group. ${ }^{18}$ In our study the length of hospital stay was 3 days in vaginal hysterectomy group and 5 days in abdominal group, which is well comparable to other studies.

\section{CONCLUSION}

It is concluded that vaginal hysterectomy in non-descent uterus have several advantages over abdominal hysterectomy in terms of less intra-operative time, less blood loss requiring blood transfusion, low abdominal discomfort, early mobility, scarless surgery, less hospital stay, low cost and present study shown that the vaginal route should be the choice of surgery for non-descent cases.

In some cases, combinations of debulking techniques are required and the surgeon needs to be familiar with them to remove larger uterus.

Present study shows that NDVH should be consider as preferred technique for the management of patients with non-descent benign diseases of the uterus. Transabdominal approach should be reserved for cases where vaginal hysterectomy is either contraindicated or when conversation is required in difficult NDVH.

Funding: No funding sources Conflict of interest: None declared

Ethical approval: The study was approved by the Institutional Ethics Committee

\section{REFERENCES}

1. Meikle SF, Nugent SW, Oleans M. Complications and recovery from laparoscopy-assisted vaginal hysterectomy compared with abdominal and vaginal hysterectomy. Obstet Gynecol. 1997;89:304-11.

2. ACOG Committee Opinion No. 444: Choosing the route of hysterectomy for benign disease. Obstet Gynaecol 2009;114(5):1156-8.

3. Wu JM, Wechter ME, Geller EJ, Nguyen TV, Visco AG. Hysterectomy rates in the United States, 2003. Obstet Gynaecol. 2007;110(5):1091-5. 
4. Under JB. Vaginal hysterectomy for the woman with moderately enlarged uterus weighing 200 to 700 grams. Am J Obstet Gynecol. 1999;180:1337-44.

5. McCracken G, Hunter D, Morgan D, Price JH. Comparison of laparoscopic-assisted vaginal hysterectomy, total abdominal hysterectomy and vaginal hysterectomy. Ulster Med J. 2006;75(1):548.

6. Sheth SS. Vaginal hysterectomy. In; Puri R, Malhotra N, eds. Operative Obstetrics and Gynaecology. 1st ed. New Delhi. Jaypee Brother's Medical Publishers. 2009: 499-510.

7. Thomas GS. Hysterectomy. Eds. Berek and Novak's Gynecology. 14th Edition. 2007;22(c):805.

8. Dewan R, Agarwal S, Minocha B, Sen SK. Nondescent vaginal hysterectomy: an experience. J Obstet Gynaecol India. 2004;54(4):376-8.

9. Bharatnur S. Comparative study of abdominal versus vaginal hysterectomy in non-descent cases. Internet $\mathrm{J}$ Gynaecol Obstet. 2011;15(2):1528-39.

10. Bhadra B, Choudary AP, Tolassaria A, Nupur N. Non-descent vaginal hysterectomy (NDVH): personal experiences in 158 cases. AL Ameen J Med Sci. 2011;4(1):23-7.

11. Mehla S, Chutani N, Gupta M. Non-decent vaginal hysterectomy: personal experience of 105 cases. Int J Reprod Contracept Obstet Gynecol. 2015;4(1):61-5.

12. Purohit RK, Tripathy PN, Patnaik AK. Vaginal hysterectomy using electrocautery and Purohit approach to uterine artery. J Obstet Gynaecol India. 2003;53:475-8.
13. Dorsey JA, Steinberg EP, Holtz PM. Clinical indications for hysterectomy route; patient characteristics or physician preference? Am J Obstet Gynaecol. 1995;173:1452-60.

14. Garry R, Fountain J, Mason S, Napp V, Brown J, Hawe J, et al. The evaluate study: two parallel randomized trials, one comparing laparoscopic with abdominal hysterectomy and the other comparing laparoscopic with vaginal hysterectomy. BMJ. 2004;328:129-33.

15. Chen B, Ren DP, Li JX, Li CD. Comparison of vaginal and abdominal hysterectomy: a prospective non-randomized trial. Pak J Med Sci. 2014;30(4):875-9.

16. Aniuliene R, Varzgaliene L, Varzgalis M. A comparative analysis of hysterectomies. Medicina (Kaunas). 2007;43:118-24

17. Goswami V, Singh DR. Impact of mobile phone addiction on adolescent's life: A literature review. Int J Home Sci.2016;2(1):69-74.

18. Joshi SA. Comparative study of vaginal hysterectomy and abdominal hysterectomy in nondescent uterus. Indian J Obstetr Gynecol Res. 2016;3(4):379-82.

Cite this article as: Singh S, Gajbhiye V. Vaginal hysterectomy a safe option in non-descent uterus as compared to abdominal hysterectomy. Int J Reprod Contracept Obstet Gynecol 2019;8:1162-6. 